\title{
Climate Change: Agriculture and Hunger
}

\author{
J. T. Trevors
}

Received: 10 June 2009 / Accepted: 11 June 2009 /Published online: 14 August 2009

(C) Springer Science + Business Media B.V. 2009

Climate change has immense effects on agriculture, and therefore human hunger currently and in the decades ahead. Agriculture is one of the best-researched areas of applied biology, chemistry, physics and economics. Yet, in many affluent countries, the number of students studying agriculture is not increasing but decreasing. The human population is currently about 6.6 billion, with about two billion lacking the basic needs of life, and the human population increasing at about 75 million annually. The projected human population for 2050 is about 9.2 billion. The future of agriculture in a changing global climate coupled to an increasing human population has to be the priority of all countries. Agriculture will be subjected to deliver increasing yields while the biosphere is subjected to changes in growing seasons, crop selections, crop failures, storms, floods, droughts, increasing pollution, erosion and diseases, as some examples. Crops that are currently near their climate thresholds will likely decrease in yields and quality in their current locations. This is all occurring while food products are wasted in many affluent countries and become part of household garbage or composted. In many less wealthy countries, food products are destroyed or contaminated after harvest due to lack of proper infrastructure in the form of storage, refrigeration and transportation. Let us not forget that water and distribution systems are required for agricultural pro-

J. T. Trevors $(\bowtie)$

Department of Environmental Biology,

University of Guelph,

Guelph NIG 2W1 Ontario, Canada

e-mail: jtrevors@uoguelph.ca duction and processing. Conflicts and differences will continue to arise over water.

The outcome will be a lack of food security, food shortages, more expensive food, more pollution to produce and distribute food and decreased worldwide food reserves. Since rice, corn and wheat generally feeds the world, the demand for increased yields will fall on countries more distant from the equator. This will be difficult as climate change and agriculture are completely linked through average temperatures for crop production, average precipitation, increasing carbon dioxide concentrations, climate extremes, increased evaporation rates, crop diseases, water supplies and the use of fossil fuels which produce greenhouse gases. Not only is agriculture under immense pressure, but fisheries, forestry and all other ecosystems are being affected. Too many humans who generate too much pollution have assaulted the applied biology of our common, shared biosphere for too many decades. The laws of thermodynamics govern the biosphere and are inescapable.

I urge everyone who reads and publishes in Water, Air and Soil Pollution to use every opportunity to write, publish, educate and inform as many people as possible (and local, national and world leaders) about the direct links between climate change, agriculture and human population growth, and demand international cooperation and action to prevent human suffering and death. As a species, we must limit our own population growth to provide a future for humanity and our common shared biosphere. Agriculture cannot support an increasing human population without an additional amount of immense global pollution. 